American Journal of Pharmaceutical Education 2019; 83 (2) Article 6535.

\title{
RESEARCH
}

\section{Curricular and Co-curricular Coverage of Leadership Competencies and the Influence of Extracurricular Engagement on Leadership Development}

\author{
Mitchell Tucci, PharmD, ${ }^{a}$ Kimhouy Tong, PharmD, ${ }^{b}$ Kelly Chia, PharmD, ${ }^{c}$ Margarita DiVall, PharmD, \\ MEd, BCPS ${ }^{\mathrm{a}, \mathrm{d}}$ \\ ${ }^{a}$ Northeastern University School of Pharmacy, Boston, Massachusetts \\ ${ }^{\mathrm{b}}$ Hartford Hospital, Hartford, Connecticut \\ ${ }^{\mathrm{c}}$ VA Health Care System, Boston, Massachusetts \\ ${ }^{\mathrm{d}}$ Editorial Board Member, American Journal of Pharmaceutical Education, Arlington, Virginia
}

Submitted May 22, 2017; accepted August 23, 2017; published March 2019.

Objective. To evaluate coverage of leadership-related competencies in a Doctor of Pharmacy (PharmD) curriculum and the impact of co-curricular and extracurricular experiences on students' leadership perceptions and self-efficacy.

Methods. Course syllabi were used to comprehensively map the PharmD curriculum to 11 competencies related to the Leadership CAPE outcome. A survey was developed and administered to all first year through fourth year pharmacy (P1-P4) students to evaluate their leadership experience and engagement, and to assess their attitudes and self-efficacy in 11 leadership competencies. Descriptive statistics were used to evaluate student level of engagement in leadership activities and the Mann-Whitney U test was used to compare students' attitudes and self-efficacy based on the extent of leadership engagement.

Results. Curriculum mapping revealed that all competencies were covered in at least one course at the introductory or reinforce levels. There were 362 students ( $68 \%$ of all PharmD students) who completed the survey. When responses from students who reported active engagement in pharmacy student organizations (defined as e-board member or chair of committee, $\mathrm{N}=142$ or $39 \%$ of respondents) were compared to the rest of the cohort, statistically significantly better attitudes and self-efficacy were seen in 7 of 11 competencies. Perceptions and self-efficacy of the 72 students (19.9\%) who reported active engagement in nonpharmacy organizations did not significantly differ from those not actively involved in any organizations. Conclusion. The leadership competencies curriculum mapping exercise was useful in identifying gaps in coverage and depth of coverage, inconsistencies in course objectives accurately reflecting coverage of leadership topics and competencies, and considerations that should be given to co-curricular leadership development. Active leadership engagement in pharmacy student organizations should be encouraged because of associated improved leadership perceptions and self-efficacy.

Keywords: leadership, competencies, curriculum, CAPE outcomes, student development

\section{INTRODUCTION}

The dynamic role of pharmacy in health care has led to an increased appreciation for the importance of developing leaders within the pharmacy profession. In 2013, the Center for the Advancement of Pharmacy Education (CAPE) released its Educational Outcomes guide that included the development of professional skills and attri-

Corresponding Author: Margarita DiVall, Northeastern University School of Pharmacy, 140 The Fenway, R218A, Boston, MA 02115. Tel: 617-373-5370. E-mail: m.

divall@northeastern.edu

Note: At the time of manuscript submission, Drs. Tucci, Tong, and Chia were students at Northeastern University School of Pharmacy. butes, leadership, pharmacy knowledge and skills. ${ }^{1}$ The inclusion of leadership development complements similar efforts in other health care professions such as nursing, as well as competencies established to promote leadership practices that support interprofessional collaborations. ${ }^{2,3}$

Studies have identified critical time points at which leadership qualities can be cultivated. For example, surveys administered to pharmacy interns prior to and after internships show that their perceptions of leadership align with their mentor over the course of their training. ${ }^{4}$ A longitudinal study of students enrolled in a pharmacy leadership Master's program found that pharmacy leaders continue to develop skills through formal and mentor-based education. ${ }^{5}$

While participation in extracurricular organizations can provide students with hands-on leadership practice, 


\section{American Journal of Pharmaceutical Education 2019; 83 (2) Article 6535.}

curricular interventions are less well developed. ${ }^{6}$ Only recently have institutions begun to incorporate methods aimed to produce these leadership outcomes into the academic curriculum. The University of British Columbia used a virtual and interprofessional case-based strategy to improve collaborative leadership skills. ${ }^{7}$ A student-led leadership course was implemented at the University of Iowa to circumvent resource limitations. ${ }^{8}$ Feller and colleagues identified 191 opportunities for leadership development through their systematic review of pharmacy education journals and school websites; however, they recommended that additional steps to incorporate activities that nurture leadership be implemented at the institutional level. ${ }^{9}$ Research into nursing leadership education reached similar conclusions regarding the need for increased curricular development. $^{2}$

Janke and colleagues published a framework of considerations for student leadership development and assessment. ${ }^{6}$ The authors suggested 11 specific leadership competencies within the three domains of leadership knowledge, personal leadership commitment, and leadership skills development. Students who have attained leadership knowledge can identify pharmacy leadership and its importance, as well as distinguish leadership from management. Students should also be familiar with the characteristics of successful leaders. Leadership commitment is demonstrated through self-awareness of personal values and endeavors to personally develop leadership abilities. Competencies related to skills development comprise the ability to develop a shared vision, collaborate on, and lead projects. Recognition of organizational structures and change processes are also incorporated into competencies related to leadership skills development. These competencies provide defined objectives related to CAPE's more general leadership educational outcome centered on "[demonstrating] responsibility for creating and achieving shared goals, regardless of position." Importantly, Janke and colleagues emphasized the need of vertical and horizontal integration of student leadership development throughout their education. ${ }^{6}$ The authors provided a set of principles to guide curricula design, and identified important opportunities to introduce and longitudinally reinforce student leadership development such as during orientation, in the curriculum, and within co-curricular activities.

However, despite examples of didactic activities intended to develop leadership, specific attempts to measure curricular incorporation of student leadership development are still limited. Indeed, much of the recent research into pharmacy leadership is centered on evaluating specific new curricular initiatives, rather than holistically assessing the incorporation of leadership development into the curriculum. For example, questionnaires have been used to evaluate both pharmacy faculty and student utilization and perception of a curricular continuing professional development framework designed to develop leadership skills. ${ }^{10,11}$ Curricular mapping has been previously used to assess the incorporation of leadership objectives ${ }^{12}$ but as many students develop leadership qualities in co-curricular and extracurricular settings, there exist few studies on how pharmacy schools measure and record the development of leadership in these environments. ${ }^{13-15}$

This study aimed to determine the alignment of the Northeastern University PharmD curriculum with established leadership competencies ${ }^{6}$ through gap analysis and identify additional opportunities for leadership development in the curriculum and co-curricular activities (specifically student professional portfolio). Additionally, the role of extracurricular leadership engagement in shaping student perceptions and self-efficacy (one's belief in one's ability to succeed in specific situations or accomplish a task) in leadership competencies was examined. The authors hypothesized that active involvement in leadership activities, both in pharmacy and non-pharmacy professional organizations, would have a positive impact on leadership development. Furthermore, the authors anticipated improvements in leadership perceptions and self-efficacy assessments as students advance through the program.

\section{METHODS}

The Northeastern University PharmD program adapted the CAPE 2013 outcomes as ability-based programmatic outcomes in 2014. The school uses a standard syllabus template that requires faculty to indicate any CAPE outcomes covered within the course as well as the level of coverage and assessment methods. Each course has been reviewed by the curriculum committee and the mapping of all syllabi to CAPE outcomes was completed by 2015 . To accomplish the first objective of in-depth leadership competency mapping, 11 course syllabi indicating coverage of the Leadership CAPE outcome were reviewed for coverage of 11 published leadership competencies (Table 1). ${ }^{6}$ The course review evaluated course objectives, topic schedule, group and/or in class projects, and homework assignments, and was conducted independently by two investigators. Any discrepancies were adjudicated by a third investigator. Depth of coverage was rated by course instructors using existing categories within the standardized syllabus template: introductory (outcome is presented at the introductory level, no prior knowledge or experience is expected), reinforce (outcome is incorporated and reinforced throughout the course), and emphasis (outcome is the primary focus of 


\section{American Journal of Pharmaceutical Education 2019; 83 (2) Article 6535.}

Table 1. Curriculum Mapping of Leadership Competencies

\begin{tabular}{|c|c|c|}
\hline Leadership Competency & $\begin{array}{l}\text { Number of Courses } \\
\text { Covered }\end{array}$ & Courses \\
\hline \multicolumn{3}{|l|}{ Leadership Knowledge (What is leadership?) } \\
\hline Competency 1: Explain the importance of leadership in pharmacy. & 1 & PCM \\
\hline $\begin{array}{l}\text { Competency 2: Recognize that leadership comes from those } \\
\text { with and without titles. }\end{array}$ & 1 & PCM \\
\hline Competency 3: Distinguish between leadership and management. & 1 & PCM \\
\hline $\begin{array}{l}\text { Competency 4: Describe the characteristics, behaviors and practices } \\
\text { of effective leaders. }\end{array}$ & 1 & PCM \\
\hline \multicolumn{3}{|l|}{ Personal Leadership Commitment (Who am I as a leader?) } \\
\hline Competency 5: Demonstrate self-awareness in leadership. & 1 & PCM \\
\hline Competency 6: Engage in personal leadership development. & 1 & PCM \\
\hline \multicolumn{3}{|c|}{ Leadership Skill Development (What skills and abilities do I need to be an effective leader?) } \\
\hline Competency 7: Develop a shared vision for an initiative or project. & 8 & $\begin{array}{l}\text { PCM, CDM 1-4 seminars, } \\
\text { EBM, EBI, EBI Lab }\end{array}$ \\
\hline Competency 8: Collaborate with others. & 8 & $\begin{array}{l}\text { PCM, CDM 1-4 seminars, } \\
\text { EBM, EBI, EBI Lab }\end{array}$ \\
\hline Competency 9: Lead members of a team. & 8 & $\begin{array}{l}\text { PCM, CDM 1-4 seminars, } \\
\text { EBM, EBI, EBI Lab }\end{array}$ \\
\hline Competency 10: Develop knowledge of organizational culture. & 1 & PCM \\
\hline Competency 11: Outline change processes. & 0 & \\
\hline
\end{tabular}

Abbreviations: $\mathrm{PCM}=$ Pharmacy Care Management, $\mathrm{CDM}=$ Comprehensive Disease Management, EBM=Evidence-Based Medicine, EBI= Educational and Behavioral Interventions.

the course and an integral part of the course competencies). In addition, to capture co-curricular expectations, student professional portfolio template was evaluated and mapped to leadership competencies. The school requires all PharmD students to maintain a professional reflective student development portfolio. As part of the portfolio, students are expected to submit written reflections related to attainment of two to three CAPE educational outcomes each semester. Specific outcomes assigned to each semester are determined based on the didactic and experiential work during that time.

To achieve the second objective, a cross-sectional survey was developed and administered to evaluate student perceptions and self-efficacy in leadership competencies. All students enrolled in the professional years of the pharmacy school program (P1-P4) were invited to participate in a web-based anonymous survey using the Qualtrics platform (Provo, UT) in November 2016. Participation was voluntary, and students were incentivized with the opportunity to win one of $20 \$ 15$ Starbucks gift cards. The survey was open for two weeks and a reminder was sent a week after the original invitation. The survey collected information about student involvement in pharmacy and non-pharmacy organizations. To capture the extent of involvement, students were asked to self-report whether they participated in pharmacy or non-pharmacy organizations, and further, whether they held an elected office or e-board position, served as a chair of a committee or event, or just attended meetings. Additionally, students responded to a series of statements that corresponded to the 11 leadership competencies using a 4-point Likert scale where $1=$ strong disagreement, 2 =disagreement, $3=$ agreement, and $4=$ strong agreement. The survey instrument consisted of 19 positively and negatively stated items that were developed by the study investigators and not externally validated (Appendix 1).

Survey responses were evaluated using descriptive statistics. Comparisons in survey responses by year in the program were analyzed using the Kruskal-Wallis test for comparison among four student cohorts and the MannWhitney U test to compare students who were actively engaged in pharmacy leadership activities compared to the rest of the cohort. Active engagement was defined as holding an e-board position or service as the chair of a committee or an event. Scale reliability was estimated using Cronbach's alpha coefficient of internal consistency, which indexes homogeneity of scale items for the scale as a whole. Exploratory factor analysis was applied to the survey responses to determine the number of underlying components or factors responsible for the 


\section{American Journal of Pharmaceutical Education 2019; 83 (2) Article 6535.}

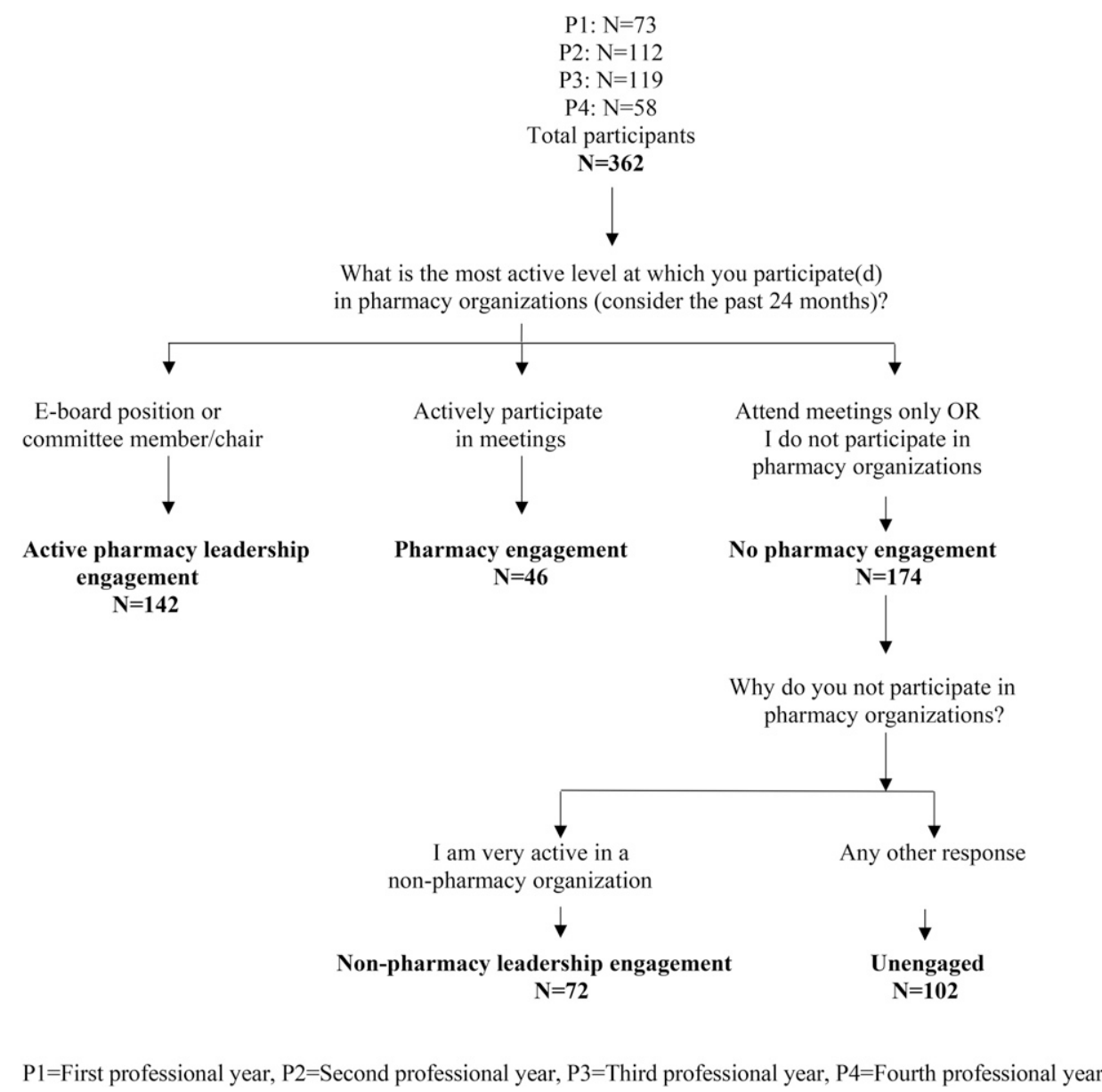

Figure 1. Student Survey Participant Characteristics

covariation of the data within the scale. The project was approved by Northeastern University Investigational Review Board.

\section{RESULTS}

Syllabi mapping revealed 10 out of $11(91 \%)$ leadership competencies that were accounted for in the reviewed courses (Table 1). Ninety-one percent of leadership competencies were covered in a single course called Pharmacy Care Management (PCM). Competency 11 (outline change processes) was not covered in any of the 11 reviewed course syllabi. However, during discussions with the PCM course coordinator and the curriculum committee, it was discovered that this course discusses Kotter's model for leading change ${ }^{16}$ and a recommendation was made to amend the syllabus to reflect the corresponding competency. Competencies 1 to 6 , representing the domains of leadership knowledge and personal leadership commitment, were only covered in PCM. All competencies were covered at an introductory level, except "distinguish between leadership and management," which was reinforced throughout the course. The remainder of the evaluated courses covered competencies 7, 8 and 9 representing leadership skill development. These courses largely used group work and projects to develop leadership skills. Course instructors reported that the leadership competencies were reinforced through the collaborative group work but were not the emphasis of these courses. The Introductory Pharmacy Practice Experience (IPPE) and Advanced Pharmacy Practice Experience (APPE) courses were previously identified as covering the CAPE Leadership outcome and were thus initially included in the evaluation. However, no definitive mapping to specific leadership competencies could be ascertained due to the variability of each student experience and the lack of specificity regarding leadership competencies and activities in the syllabi.

As part of the professional portfolio, a co-curricular requirement, students are asked to reflect on their leadership abilities and commitment during pre-pharmacy year 2 fall semester. Students in the P1-P4 years of the program may choose from several CAPE outcomes (including Leadership) to reflect on after completing each IPPE and APPE. The reflections are structured using prompts 


\section{American Journal of Pharmaceutical Education 2019; 83 (2) Article 6535.}

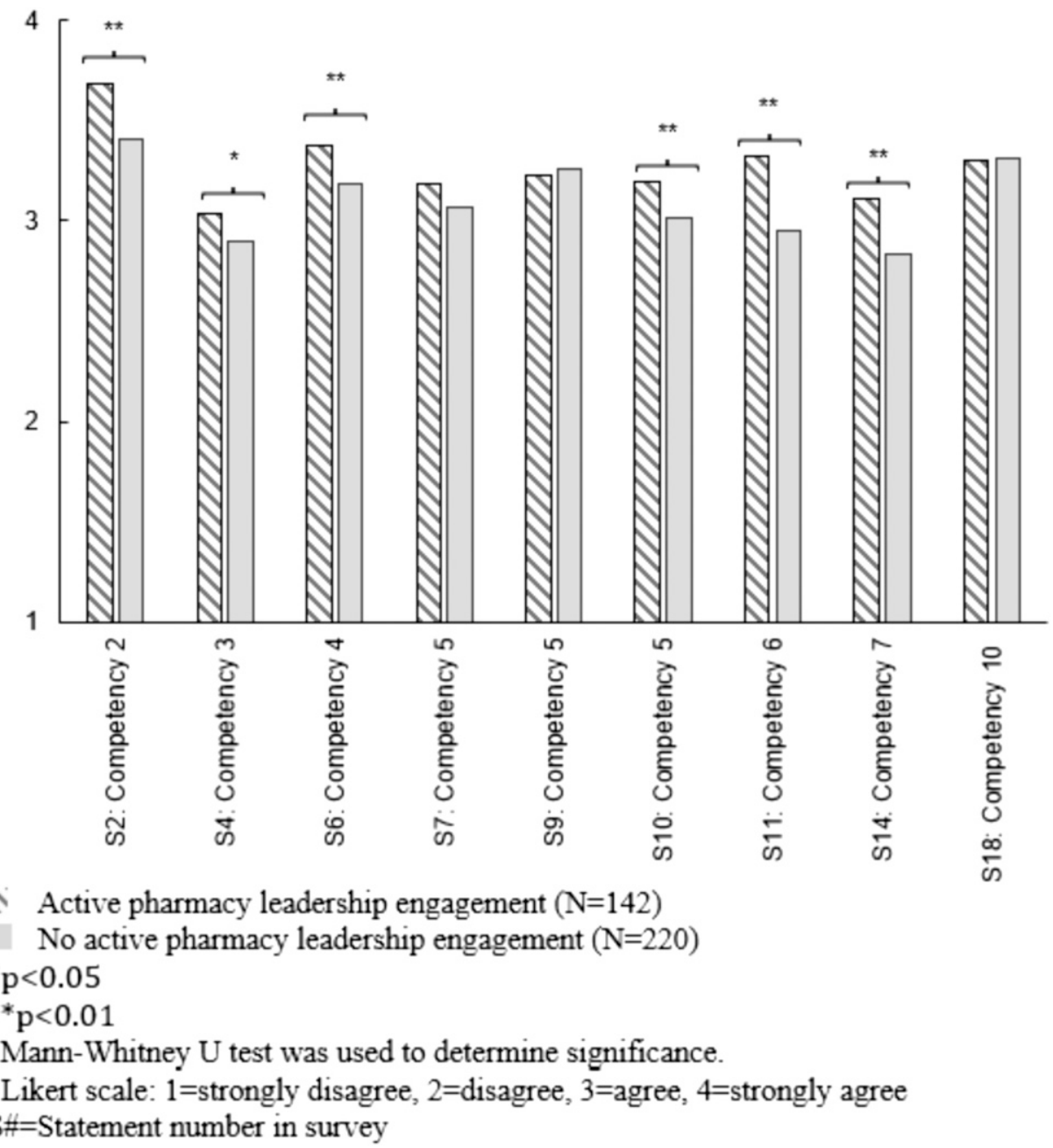

Figure 2. Student Perceptions (Mean Scores) of Positive Leadership Statement

allowing students to reflect on competencies identified in the second domain by Janke and colleagues ${ }^{6}$ answering the question, "Who am I as a leader?" Additionally, as part of the portfolio expectations, students are required to document attendance and reflect on at least two professional pharmacy-related events each semester. Many of these events provide opportunities for students to achieve leadership competencies, specifically competencies 1 to 4 which are categorized in the first domain of leadership knowledge and answer the question, "What is leadership?"

The survey was completed by 362 students $(68 \%)$. The breakdown of cohorts and students' extent of leadership engagement can be seen in Figure 1. Highest response rates for cohorts were seen in the P2 and P3 years. When students who self-reported active leadership engagement with pharmacy organizations (defined as holding an e-board position or service as the chair of a committee) were compared to the rest of the cohort, statistically significantly better attitudes and self-efficacy were seen in 7 of 11 competencies (Figures 2 and 3). Six competencies represented the domains of leadership knowledge and personal leadership commitment, with only one competency reflecting leadership skill development. Overall, there was a trend for improved perceptions and self-efficacy among those with active pharmacy leadership compared to the rest of participants for all but two statements: "Charisma is required to be an effective leader" and "With my previous Co-op(s) or job(s), I have a good understanding of how the organization is structured and the values and beliefs of the organization/department." Attitudes and self-efficacy of students who reported active engagement with non-pharmacy organizations did not significantly differ from those who reported no active leadership participation.

Mean scores based on responses to leadership statements from each of the cohorts are shown in Table 2. Overall, seven of the leadership statements representing five leadership competencies within two domains were found to be significantly different across the cohorts; 


\section{American Journal of Pharmaceutical Education 2019; 83 (2) Article 6535.}

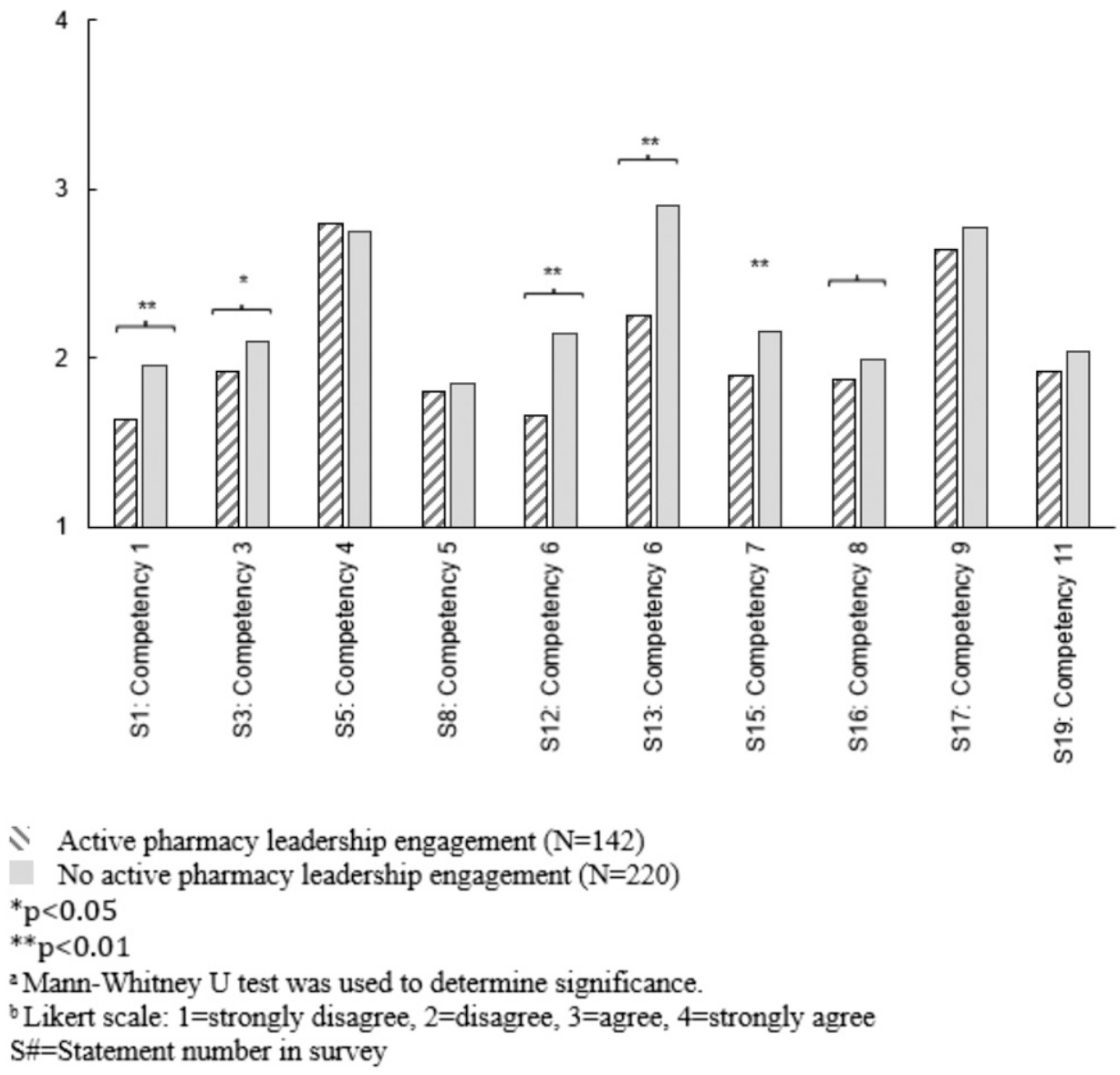

Figure 3. Student Perceptions (Mean Scores) of Negative Leadership Statements

however, there was not a clear progression from P1 to P4 years. Analysis of the overall average scores revealed several competencies as potential targets for increased exposure or development. For items associated with competencies $3,4,6,7$, and 9 , the average response to a specific statement evaluating perception of self-efficacy fell within 2-3 on the Likert scale, indicating neutrality to the statement (Table 1).

Scale reliability analysis produced an overall Cronbach alpha of 0.55 , which is acceptable, but suboptimal as for new scale development, Cronbach alpha of $>0.65$ is desirable. ${ }^{17}$ The factor analysis produced extraction factors 0.7 or above for eight items; and between 0.5 and 0.7 for the remaining 11 items. Factor analysis identified six components of the scale, which explained $62 \%$ of the variance.

\section{DISCUSSION}

Leadership development among health professional students plays a critical role in the advancement of future health care practices. ${ }^{18}$ According to the Core Competencies for Interprofessional Collaborative Practice, leadership competency among health professionals supports teamwork practices when working in an interdisciplinary team. ${ }^{19}$ Thus, ongoing evaluation of the incorporation of leadership skill development within accredited professional programs is necessary to align student outcomes with these recommendations.

The results of this study aimed to measure the integration of leadership development within the Northeastern University PharmD program via two complementary strategies. The first component of this study aimed to identify gaps in leadership development in the program through a curriculum mapping process that compared course objectives listed in current course syllabi against 11 leadership competencies identified by Janke and colleagues. ${ }^{6}$ The results of the curriculum mapping demonstrated that all leadership competencies were addressed in the curriculum; however, the depth of coverage was either at the introductory or reinforcement levels. Coverage of one competency was not recognized until discussion with course instructor, highlighting the need to involve faculty in all curriculum mapping activities to validate the mapping to ensure it accurately represents course content and outcomes. ${ }^{20}$ Analysis revealed that the majority of the leadership competencies were covered in one didactic 


\section{American Journal of Pharmaceutical Education 2019; 83 (2) Article 6535.}

Table 2. Student Perceptions of Leadership Statements by Cohort

\begin{tabular}{|c|c|c|c|c|c|c|}
\hline \multirow[b]{2}{*}{ Survey Statement } & \multicolumn{6}{|c|}{ Average Score $^{\mathrm{b}}$} \\
\hline & $\begin{array}{c}\text { Entire Cohort } \\
\quad \mathrm{N}=362\end{array}$ & $\begin{array}{c}P 1 \\
N=73\end{array}$ & $\begin{array}{c}\mathrm{P2} \\
\mathrm{N}=112\end{array}$ & $\begin{array}{c}\mathrm{P3} \\
\mathrm{N}=119\end{array}$ & $\begin{array}{c}\mathbf{P 4} \\
\mathrm{N}=58\end{array}$ & $p$ value $^{\mathrm{a}}$ \\
\hline \multicolumn{7}{|l|}{ Leadership Knowledge (What is leadership?) } \\
\hline Domain average positively stated items & 3.3 & 3.2 & 3.2 & 3.3 & 3.3 & \\
\hline Domain average negatively stated items & 2.2 & 2.3 & 2.4 & 2.0 & 2.1 & \\
\hline Practicing pharmacy does not require leadership development. ${ }^{\mathrm{c}}(\mathrm{C} 1)$ & 1.8 & 1.7 & 2.0 & 1.8 & 1.7 & .08 \\
\hline $\begin{array}{l}\text { Pharmacy students, pharmacists and technicians can all be } \\
\text { successful leaders. (C2) }\end{array}$ & 3.5 & 3.6 & 3.5 & 3.5 & 3.6 & .09 \\
\hline Leadership and management are two names for the same role. ${ }^{\mathrm{c}}(\mathrm{C} 3)$ & 2.0 & 2.2 & 2.2 & 1.9 & 1.8 & $<.01^{\mathrm{a}}$ \\
\hline $\begin{array}{l}\text { Leaders create the vision, managers deal with day-to-day } \\
\text { activities. (C3) }\end{array}$ & 2.9 & 2.9 & 2.9 & 3.1 & 2.9 & $<.01^{\mathrm{a}}$ \\
\hline Charisma is required to be an effective leader. ${ }^{c}(\mathrm{C} 4)$ & 2.8 & 3.0 & 3.0 & 2.5 & 2.6 & $<.01^{\mathrm{a}}$ \\
\hline $\begin{array}{l}\text { Leadership can be developed, even in people who do not have } \\
\text { natural leadership abilities. (C4) }\end{array}$ & 3.3 & 3.3 & 32 & 3.3 & 3.3 & .27 \\
\hline \multicolumn{7}{|l|}{ Personal Leadership Commitment (Who am I as a leader?) } \\
\hline Domain average positively stated items & 3.2 & 3.3 & 3.1 & 3.1 & 3.2 & \\
\hline Domain average negatively stated items & 2.1 & 2.0 & 2.1 & 2.2 & 2.1 & \\
\hline $\begin{array}{l}\text { I possess characteristics and exhibit behaviors that will make } \\
\text { me a good leader. (C5) }\end{array}$ & 3.1 & 3.1 & 3.1 & 3.1 & 3.2 & .69 \\
\hline I don't know why it's hard for me to work in group projects. ${ }^{\mathrm{c}}$ (C5) & 1.8 & 1.8 & 1.8 & 1.9 & 1.8 & .67 \\
\hline I can admit when I have made a mistake. (C5) & 3.3 & 3.4 & 3.2 & 3.2 & 3.3 & $.02^{\mathrm{a}}$ \\
\hline I reflect on the way I lead in school or work projects. (C5) & 3.1 & 3.3 & 3.0 & 3.0 & 3.2 & $.01^{\mathrm{a}}$ \\
\hline I enjoy learning about how I can become a better leader. (C6) & 3.1 & 3.3 & 3.1 & 3.0 & 3.0 & .14 \\
\hline I'm not interested in taking on leadership roles. ${ }^{\mathrm{c}}$ (C6) & 1.9 & 1.9 & 2.0 & 2.0 & 1.9 & .29 \\
\hline $\begin{array}{l}\text { I attend only the minimum number of events required to complete } \\
\text { my portfolio. }{ }^{\mathrm{c}} \text { (C6) }\end{array}$ & 2.6 & 2.4 & 2.6 & 2.8 & 2.7 & .57 \\
\hline \multicolumn{7}{|c|}{ Leadership Skill Development (What skills and abilities do I need to be an effective leader?) } \\
\hline Domain average positively stated items & 3.1 & 3.2 & 3.2 & 3.0 & 3.1 & \\
\hline Domain average negatively stated items & 2.2 & 2.1 & 2.2 & 2.3 & 2.1 & \\
\hline $\begin{array}{l}\text { I like working with people to develop ideas for an initiative or } \\
\text { project. (C7) }\end{array}$ & 3.0 & 3.0 & 3.0 & 2.8 & 3.0 & .17 \\
\hline $\begin{array}{l}\text { I am generally uninterested in participating in new initiatives or } \\
\text { projects. }^{c}(\mathrm{C} 7)\end{array}$ & 2.0 & 1.9 & 2.1 & 2.2 & 2.0 & .08 \\
\hline I have a difficult time working with others on group projects. ${ }^{\mathrm{c}}$ (C8) & 1.9 & 1.9 & 2.0 & 2.0 & 1.8 & .19 \\
\hline I tend to go with the flow of a project. ${ }^{\mathrm{c}}$ (C9) & 2.7 & 2.6 & 2.8 & 2.8 & 2.6 & $.04^{\mathrm{a}}$ \\
\hline $\begin{array}{l}\text { With my previous co-op(s) or job(s), I have a good understanding of } \\
\text { how the organization is structured and the values and beliefs of } \\
\text { the organization/ department. (C10) }\end{array}$ & 3.3 & 3.4 & 3.4 & 3.2 & 3.2 & $.01^{\mathrm{a}}$ \\
\hline $\begin{array}{l}\text { I am at a loss when it comes to figuring out how to turn an idea } \\
\text { into a reality. }{ }^{\mathrm{c}}(\mathrm{C} 11)\end{array}$ & 2.0 & 1.9 & 2.0 & 2.1 & 2.0 & .24 \\
\hline
\end{tabular}

Abbreviations: $\mathrm{P} 1=$ First professional year, $\mathrm{P} 2=$ Second professional year, $\mathrm{P} 3=$ Third professional year, $\mathrm{P} 4=$ Fourth professional year, $\mathrm{CH}=$ competency number (Table 1) linked to the statement

${ }^{a}$ Kruskal-Wallis test was used to determine significance, defined as $p<.05$.

${ }^{\mathrm{b}}$ Likert scale: $1=$ strongly disagree, $2=$ disagree, $3=$ agree, $4=$ strongly agree

${ }^{\mathrm{c}}$ Negatively stated items.

course - Pharmacy Care Management, which at the time of the study was taught during the second semester of P2 year. While the course syllabi identify CAPE Leadership outcome to be covered at the emphasis level, the instructor selected either introductory or reinforcement level of coverage for more specific competencies, which warrants further discussion. The late timing of the course in the curriculum provides little opportunity for vertical and horizontal integration of leadership skills development recommended by Janke and colleagues. ${ }^{6}$ Further, though the school uses a required professional reflective student development portfolio to document co-curricular activities, 


\section{American Journal of Pharmaceutical Education 2019; 83 (2) Article 6535.}

reflection on leadership was required only in pre-professional pharmacy year and was only recommended as one of the outcomes to reflect on after each experiential rotation and co-curricular activity. Since preceptors and mentors during rotation can have a significant impact on students' leadership development, ${ }^{4}$ it is important to facilitate their reflection on their leadership commitment and skills at these points of their education.

Survey results were also considered in terms of differences among the four professional year cohorts. Since the majority of didactic leadership knowledge and skills development occurs in the Pharmacy Care Management course, students who have not yet taken this course in their professional years were, therefore, not exposed to activities related to these competencies. As expected, student self-reported perceptions of leadership competencies and related self-efficacy markedly improved between the P2 and P3 cohort, especially in the subdomains of leadership knowledge. However, overall, there was no clear progression of competency development throughout the curriculum, indicating that extra-curricular and co-curricular activities likely influence student development, similarly to what was seen in other studies. ${ }^{4,9,21}$

Based on the results of the curriculum mapping, several recommendations were made to the curriculum committee. First, faculty were advised to confirm that their syllabi accurately reflect leadership development initiatives in the classroom. Second, a recommendation was made to move the Pharmacy Care Management earlier in the curriculum into the second semester of the P1 year, to allow the course to introduce students to leadership competencies, which can be reinforced and built on in the various team-centered activities already incorporated throughout the curriculum in the P2 and P3 years. Specific attention will be paid to leadership competencies that were identified to be weaker across all cohorts. Furthermore, the committee discussed how experiential learning during IPPEs and APPEs provides additional opportunities for leadership growth and what specific activities can be developed and required consistently across all experiences to provide a platform for developing leadership competencies and that these activities and related competencies should be clearly indicated in course syllabi. Finally, a recommendation was made to revise the portfolio reflection assignments to require reflection on the CAPE Leadership outcome each year of the curriculum during didactic or experiential semesters. While faculty advisors review and provide feedback on individual student portfolios and reflections, an aggregate analysis of reflections related to Leadership outcome should be performed by the sub-group of the curriculum committee after changes are implemented to corroborate student self-reported perceptions regarding leadership competencies.
The second component of the study aimed to capture the self-reported leadership competency of the students in the PharmD program. The results of the survey demonstrated that students who identified as actively engaged in professional pharmacy organizations had significantly improved self-efficacy related to leadership competencies in comparison to those identified as not actively engaged (Figures 2 and 3). These results corroborate other recent findings, including a survey administered to pharmacy students by Phillips and colleagues in which the top identified reason for pursuing a leadership position in a professional pharmacy organization was for personal leadership development. ${ }^{19}$ Differences in perceptions and self-competency among students actively engaged in pharmacy organizations were seen in the sub-domains of leadership knowledge and personal leadership commitment, but not in leadership skills. These results could possibly indicate that factors other than pharmacy organization engagement may contribute to skill development among students. For example, students within the Northeastern School of Pharmacy also have the unique opportunity to complete their IPPE requirements through the university's unique cooperative education program. This co-op program requires students to successfully complete three semesters of full-time employment as a pharmacy intern. In addition to the required community and institutional pharmacy IPPE, students have the early opportunity to tailor their co-op with an elective experience such as specialty pharmacy, pharmaceutical industry, managed care, and other settings. The relative increased depth and breadth of the co-op model compared to typical IPPE, along with the opportunity to personalize these early pharmacy experiences, may provide unique leadership development opportunities that directly and differentially impact student leadership skill development.

Surprisingly, students who were identified as actively engaged in non-pharmacy organizations did not exhibit similar levels of leadership competency self-efficacy when compared to students with active pharmacy leadership engagement. While there were trends in improved perceptions and self-efficacy when students engaged in non-pharmacy related organizations compared to completely unengaged students, none of the results were statistically significant. It could be that the relatively small sample size of students reporting outside of pharmacy engagement $(n=72$ students, $20 \%$ of survey respondents or $13.5 \%$ of the pharmacy students invited to participate) was insufficient to determine statistical significance. Also, these non-pharmacy organizations, which include fraternities, sororities, ethnic culture clubs and religious groups may devote more time to social activities such as networking events or mixers, and less time to goal-directed enterprises 


\section{American Journal of Pharmaceutical Education 2019; 83 (2) Article 6535.}

(eg, community improvement initiatives). Comparisons of the types of activities staged by pharmacy and nonpharmacy groups could be illuminating and may be a subject for further investigation.

Limitations of the curricular mapping include the lack of generalizability of this data across other institutions, as the data from this study was collected from one pharmacy school's present curriculum. In addition, the mapping was performed using course syllabi and not all instructors and preceptors were available for clarifications (eg, specific IPPE and APPE courses). Our mapping did not account for all co-curricular activities that may affect student leadership development since we only focused on what is required by our professional portfolio and many students may go above and beyond these requirements. The survey statements used to represent the 11 competencies were not externally validated and may have incompletely or inaccurately captured student selfefficacy and perceptions. Further, reliability and factor analyses indicate that the survey reliability and validity needs to be improved by reviewing and revising the items and establishing external and construct validity. Since the survey was conducted on a voluntary basis, the possibility of self-selection bias cannot be ignored. While there is learning outcomes data available from several sources, such as ExamSoft and our experiential management system, the data is not granular enough to identify achievement of the 11 competencies as the mapping of our assessments and evaluation tools is limited to CAPE Leadership outcome. The unique student profile at Northeastern may also limit application of this study's findings to other institutions. For example, a large proportion of students are admitted to the pharmacy school as freshmen, and matriculate into the professional phase of the program during their third year in college. As such, Northeastern University pharmacy students are much younger than the national average, with $95.9 \%$ of the 2016 graduating class reporting that they are under 25 years old vs the national average of $45.2 \% .^{22,23} \mathrm{Ad}-$ ditionally, it is unknown whether Northeastern University's IPPE Co-op experience program leads to different leadership development effects in comparison to the traditional IPPE model. Regardless, the survey instrument may serve as a template that other institutions can tailor to measure student self-efficacy perceptions of leadership competency.

Future research studies should include determining the contribution of other factors to student leadership development such as IPPEs and APPEs and re-evaluation of student perceptions and self-efficacy after curricular and co-curricular changes to enhance student leadership development.

\section{CONCLUSION}

The application of syllabi curriculum mapping is a valuable tool to identify areas for improvement for student leadership development within pharmacy school curricula. While the results of the curricular mapping strategy in this paper are specific to the Northeastern School of Pharmacy, other pharmacy schools can us our approach as a framework to conduct a systematic gap analysis of where and how leadership development is incorporated into their curricula. In addition, active engagement of students in professional pharmacy organizations should be strongly encouraged to further develop leadership competencies.

\section{ACKNOWLEDGMENTS}

The authors would like to acknowledge funds from the Northeastern University Undergraduate Research and Creative Endeavor Award and Dr. Jennifer Kirwin for her guidance with curriculum mapping and gap analysis and manuscript preparation.

\section{REFERENCES}

1. Medina MS, Plaza CM, Stowe CD, et al. Center for the Advancement of Pharmacy Education (CAPE) educational outcomes 2013. Am J Pharm Educ. 2013;77(8):Article 162.

2. Morrow K. Leadership curricula in nursing education: a critical literature review and gap analysis. J Nurs Educ. 2015;54(7):367-371.

3. Fitzpatrick JJ. Nursing leadership and research on patient outcomes: moving the profession forward toward better understanding of our nursing work. Appl Nursing Res. 2017;34:70. 4. Vestergaard S, Nørgaard LS, Traulsen JM, Kaae S. Pharmacy interns' perception of their professional role. Am J Pharm Educ. 2017;81(1):Article 10.

5. Achsah P, Avani D, Phouc AN, et al. Evaluating pharmacy leader development through the seven action logics. Am J Health Syst Pharm. 2016;73(2):82-85.

6. Janke KK, Nelson MH, Bzowyckyj AS, et al. Deliberate Integration of student leadership development in doctor of pharmacy programs. Am J Pharm Educ. 2016;80(1):Article 2.

7. Wong E, Leslie JJ, Soon JA, Norman WV. Measuring interprofessional competencies and attitudes among health professional students creating family planning virtual patient cases. BMC Med Educ. 2016;16(1):273.

8. Patterson BJ, Garza OW, Witry MJ, et al. A leadership elective course developed and taught by graduate students. Am J Pharm Educ. 2013;77(10):Article 223.

9. Feller TT, Doucette WR, Witry MJ. Assessing opportunities for student pharmacist leadership development at schools of pharmacy in the United States. Am J Pharm Educ. 2016;80(5): Article 79.

10. Patterson BJ, Chang EH, Witry MJ, Garza OW, Trewet CB. Pilot evaluation of continuing professional development tool for developing leadership skills. Res Social Adm Pharm. 2013;9(2):222-229.

11. O’Brocta R, Abu-Baker A, Budukh P, Gandhi M, Lavigne J, Birnie C. A continuous professional development process for firstyear pharmacy students. Am J Pharm Ed. 2012;76(2):Article 29. 12. Ramia E, Salameh P, Btaiche IF, Saad AH. Mapping and assessment of personal and professional development skills in a pharmacy curriculum. BMC Med Educ. 2016;16:19. 


\section{American Journal of Pharmaceutical Education 2019; 83 (2) Article 6535.}

13. Chesnut R, Tran-Johnson J. Impact of a student leadership development program. Am J Pharm Educ. 2013;77(10):Article 225. 14. Kiersma ME, Plake KS, Mason HL. Relationship between admission data and pharmacy student involvement in extracurricular activities. Am J Pharm Educ. 2011;75(8):Article 155.

15. Scott MA, McLaughlin J, Shepherd G, et al. Professional organizations for pharmacy students on satellite campuses. Am J Pharm Educ. 2016;80(5):Article 78.

16. Kotter JP. Leading Change. Boston, MA: Harvard Business School Press; 1996.

17. DeVellis RF. Scale Development: Theory and Applications. 3rd ed. Thousand Oaks, CA: SAGE Publications; 2012.

18. Garman AN, Lemak CH. Developing healthcare leaders: what we have learned, and what is next. National Center for Healthcare Leadership. 2011. http://www.nchl.org/Documents/NavLink/ NCHLDevelopingHealthcareLeaders_Nov_2011_uid11212011137292. pdf. Accessed May 22, 2017.
19. Interprofessional Education Collaborative Expert Panel. Core competencies for interprofessional collaborative practice: 2016 update. http://www.aacn.nche.edu/education-resources/IPEC-2016Updated-Core-Competencies-Report.pdf. Accessed May 22, 2017. 20. Zelenitsky S, Vercaigne L, Davies NM, et al. Using curriculum mapping to engage faculty members in the analysis of a pharmacy program. Am J Pharm Educ. 2014;78(7):Article 139.

21. Phillips JA, McLaughlin MM, Gettig JP, et al. An analysis of motivation factors for students' pursuit of leadership positions. Am J Pharm Educ. 2015;79(1):Article 8.

22. Northeastern University School of Pharmacy. AACP graduating student survey results 2016.

23. American Association of Colleges of Pharmacy. Graduating student survey national summary report. 2016. http://www.aacp.org/ resources/research/institutionalresearch/Documents/GSS_2016_ National\%20 Summary\%20Report_for\%20web\%2020160714.pdf. Accessed May 22, 2017. 


\section{American Journal of Pharmaceutical Education 2019; 83 (2) Article 6535.}

Appendix 1. Survey Statements and Corresponding Leadership Competencies

Survey Statement

Practicing pharmacy does not require leadership development.

Pharmacy students, pharmacists and technicians can all be successful leaders.

Leadership and management are two names for the same role.

Leaders create the vision, managers deal with day-to-day activities.

Charisma is required to be an effective leader.

Leadership can be developed, even in people who do not have natural leadership abilities.

I possess characteristics and exhibit behaviors that will make me a good leader.

I don't know why it's hard for me to work in group projects.

I can admit when I have made a mistake.

I reflect on the way I lead in school or work projects.

I enjoy learning about how I can become a better leader.

I'm not interested in taking on leadership roles.

I attend the minimum number of events required to complete my portfolio.

I like working with people to develop ideas for an initiative or project.

I am generally uninterested in participating in new initiatives or projects.

I have a difficult time working with others on group projects.

I tend to go with the flow of a project.

With my previous co-op(s) or job(s), I have a good understanding of how the organization is structured and the values and beliefs of the organization/ department.

I am at a loss when it comes to figuring out how to turn an idea into a reality.

\section{Leadership Competency}

Competency 1: Explain the importance of leadership in pharmacy.

Competency 2: Recognize that leadership comes from those with and without titles.

Competency 3: Distinguish between leadership and management.

Competency 3: Distinguish between leadership and management.

Competency 4: Describe the characteristics, behaviors and practices of effective leaders.

Competency 4: Describe the characteristics, behaviors and practices of effective leaders.

Competency 5: Demonstrate self-awareness in leadership.

Competency 5: Demonstrate self-awareness in leadership.

Competency 5: Demonstrate self-awareness in leadership.

Competency 5: Demonstrate self-awareness in leadership.

Competency 6: Engage in personal leadership development.

Competency 6: Engage in personal leadership development.

Competency 6: Engage in personal leadership development.

Competency 7: Develop a shared vision for an initiative or project.

Competency 7: Develop a shared vision for an initiative or project.

Competency 8: Collaborate with others.

Competency 9: Lead members of a team.

Competency 10: Develop knowledge of organizational culture.

Competency 11: Outline change processes. 